\title{
Clinical course of gastroesophageal reflux disease and impact of treatment in symptomatic young patients
}

\author{
Luigi Bonavina, ${ }^{1}$ (D) P. Marco Fisichella, ${ }^{2}$ Sravanya Gavini, ${ }^{3}$ Yeong Yeh Lee, ${ }^{4,5,6}$ \\ and Roger P. Tatum ${ }^{7}$ \\ ${ }^{1}$ Division of General and Foregut Surgery, Department of Biomedical Sciences for Health, University of Milan, IRCCS \\ Policlinico San Donato, Milano, Italy. ${ }^{2}$ Department of Surgery, Northwestern University, Feinberge School of Medicine, \\ Chicago, Illinois. ${ }^{3}$ Division of Digestive and Liver Diseases, University of Texas Southwestern Medical Center, Dallas, Texas. \\ ${ }^{4}$ School of Medical Sciences, Universiti Sains Malaysia, Kota Bharu, Malaysia. ${ }^{5}$ Gut Research Group, Faculty of Medicine, \\ Universiti Kebangsaan Malaysia, Kuala Lumpur, Malaysia. ${ }^{6}$ St George \& Sutherland Clinical School, University of New South \\ Wales, Sydney, New South Wales, Australia. ${ }^{7}$ Department of Surgery, University of Washington School of Medicine and VA \\ Puget Sound Health Care System, Seattle, Washington
}

Address for correspondence: Professor Luigi Bonavina, Division of General and Foregut Surgery, Department of Biomedical Sciences for Health, University of Milan, IRCCS Policlinico San Donato, via Morandi 30, 20097 San Donato Milanese (Milano), Italy. Luigi.bonavina@unimi.it

In symptomatic young patients with gastroesophageal reflux symptoms, early identification of progressive gastroesophageal reflux disease (GERD) is critical to prevent long-term complications associated with hiatal hernia, increased esophageal acid and nonacid exposure, release of proinflammatory cytokines, and development of intestinal metaplasia, endoscopically visible Barrett's esophagus, and dysplasia leading to esophageal adenocarcinoma. Progression of GERD may occur in asymptomatic patients and in those under continuous acid-suppressive medication. The long-term side effects of proton-pump inhibitors, chemopreventive agents, and radiofrequency ablation are contentious. In patients with early-stage disease, when the lower esophageal sphincter function is still preserved and before endoscopically visible Barrett's esophagus develops, novel laparoscopic procedures, such as magnetic and electric sphincter augmentation, may have a greater role than conventional surgical therapy. A multidisciplinary approach to GERD by a dedicated team of gastroenterologists and surgeons might impact the patients' lifestyle, the therapeutic choices, and the course of the disease. Biological markers are needed to precisely assess the risk of disease progression and to tailor surveillance, ablation, and management.

Keywords: gastroesophageal reflux disease; proton-pump inhibitors; lower esophageal sphincter; crural diaphragm; laparoscopic fundoplication; Barrett's esophagus; esophageal adenocarcinoma

Heartburn and regurgitation, the typical symptoms of gastroesophageal reflux disease (GERD), are widespread and affect up to $30 \%$ of the general population. ${ }^{1}$ Despite optimal proton-pump inhibitor (PPI) therapy, these symptoms persist in up to $40 \%$ of patients treated in primary care. ${ }^{2}$ Conversely, laparoscopic fundoplication has proven safe and effective even in elderly patients with impaired peristalsis and large paraesophageal hernias, ${ }^{3-5}$ but has been largely underused in patients with earlystage GERD. ${ }^{6}$ More recent concerns with adverse effects from long-term use of PPI and increased awareness of the preneoplastic potential of GERD and Barrett's esophagus (BE) have shifted the focus of research toward factors that might enable the prediction of the clinical course of the disease and impact treatment. Only $0.1 \%$ of patients less than 20 years old referred for upper gastrointestinal endoscopy have histologic evidence of BE. ${ }^{7}$ Given the increasing incidence of GERD worldwide by $30 \%$ every 10 years $^{8}$ and the high cumulative risk of developing molecular abnormalities and mucosal intestinalization over time, it is critical to identify the disease at an early and reversible stage of 
development, that is, in the young patients, before the appearance of irreversible esophageal epithelial changes, such as endoscopically visible BE, dysplasia, and esophageal adenocarcinoma (EAC). ${ }^{9}$

\section{Current definition of GERD}

There is currently no consensus on whether nonerosive reflux disease (NERD), erosive reflux disease (ERD), and BE are three distinct phenotypic expressions of GERD or are part of a continuous disease spectrum, and this is mainly due to the lack of robust longitudinal studies. However, GERD is increasingly being regarded as a chronic progressive disease rather than a categorical phenotype. In fact, some patients are erroneously categorized as having NERD because of previous or current treatment with PPI that may have healed mucosal lesions, and other patients are erroneously included in the spectrum of GERD in the absence of accurate pathophysiological data. ${ }^{10}$ When GERD is defined by the presence of symptoms only, ${ }^{11}$ progression is thought to affect only about one third of patients in whom PPI medications are ineffective. Patients whose symptoms are well controlled with medical therapy are usually considered risk-free unless the dosage of PPI needs to be increased over time. Generally, only patients with refractory symptoms of reflux, regurgitation, and/or dysphagia are referred for upper gastrointestinal endoscopy. Unfortunately, this may be too late to intervene to prevent the progression of the disease. Therefore, a broader definition of GERD has been introduced that takes into account the presence of endoscopic and histologic modifications of the esophageal mucosa, ranging from no visible changes to progressive erosive esophagitis and, eventually, to BE. It has been shown that nonHelicobacter pylori (H. pylori)-associated intestinal metaplasia (IM) could be present in the biopsy of the squamocolumnar junction even in patients with only slight macroscopic irregularities of the Z-line. $^{12}$

\section{Predictors of disease progression in patients with early-stage GERD}

Progressive GERD is defined by increasing symptom burden over time despite maximum PPI therapy, the development or exacerbation of esophagitis, or the development of columnar metaplasia leading to IM with goblet cells and eventually to dys- plasia and EAC. Historically, patients with GERD were diagnosed with either NERD or ERD. Later on, progression to esophagitis was shown in a subset of patients with GERD followed over 10 years ${ }^{13}$ and GERD became a spectrum disorder, with NERD at one end of the spectrum and BE and EAC at the other end. ${ }^{14,15}$ Factors that have been associated with progression of GERD include gender, family, and patient history, esophageal pathophysiology assessed by esophageal manometry and $\mathrm{pH}$ monitoring, and histology obtained from endoscopic biopsy at the Z-line. ${ }^{10-16}$

Symptoms of GERD are reported more often in women compared with men even after adjusting for body mass index (BMI), smoking, alcohol and coffee intake, and physical exercise. Also, the NERD phenotype is more commonly reported in women. ${ }^{17}$ Women have less distal esophageal acid exposure on ambulatory $\mathrm{pH} /$ impedance monitoring, and the prevalence of esophagitis, $\mathrm{BE}$, and incidence of EAC are all lower in women compared with men. ${ }^{18,19}$ Postmenopausal women are more likely to have severe reflux esophagitis and to present with $\mathrm{BE}$ than younger women. ${ }^{20,21}$ Furthermore, there is a 17-year delay in age-specific incidence of EAC reported in women compared with men. ${ }^{22}$ Animal studies show that estrogens might have an antiinflammatory effect and decrease both parietal cell mass and basal gastric acid secretion, which may explain these findings. ${ }^{23,24}$ Comorbid conditions, such as depression and anxiety, which are more common in women, may contribute to increased GERD symptom burden, although more data are needed to elucidate if peripheral/central sensitization can occur because of these conditions. ${ }^{19}$ Familial aggregation of BE results from environmental exposure, inheritance, or both ${ }^{25,26}$ and supports proper screening and surveillance in young adults at risk. In the ProGERD study, in which 2,721 patients were followed for 5 years while on maintenance PPI therapy, Malfertheiner et al. ${ }^{27}$ found by multivariate analysis that a family history of GERD and persistent symptoms and/or persistent esophagitis after PPI therapy were significantly associated with progression to more severe esophagitis (OR 1.44 and 1.53, respectively). Overall rates of GERD progression in any form were $25 \%$, and regular rather than episodic PPI use was associated with a lower risk of progression (OR 0.57). In addition, the rates of progression to BE were $5.9 \%$ for NERD, 
12.1\% for mild (Los Angeles grade A/B) esophagitis, and $19.7 \%$ for severe (grade $C / D$ ) esophagitis. Furthermore, the presence of esophagitis at baseline strongly correlated with progression to $\mathrm{BE}$. Ten percent of patients in the ProGERD study progressed to biopsy-confirmed BE during the 5-year follow-up period. A longitudinal study from Sweden, including 40 patients with GERD confirmed by 24-h $\mathrm{pH}$ monitoring and followed up to 21 years, found that the progression of the disease occurring under PPI therapy was associated with deterioration of the lower esophageal sphincter (LES). ${ }^{28}$ In another study, patients with "difficult to heal" esophagitis had more abnormal hiatal anatomy, a more defective LES, and greater esophageal acid exposure compared with patients with "healable" esophagitis. Moreover, patients with BE differed from the "difficult to heal" esophagitis group only by the degree of esophageal acid and bile exposure. ${ }^{29}$

\section{Predictors of disease progression from uncomplicated GERD to BE}

In most studies, $\mathrm{BE}$ is twice as prevalent in men than women. It is also more prevalent in older individuals, and rare in the young (less than 20 years of age), ${ }^{7}$ indicating a delay of some years before $\mathrm{BE}$ development. Nevertheless, chronic GERD remains the main risk factor for $\mathrm{BE}$, and the length of columnar metaplasia is associated with the amount and duration of reflux exposure in the distal esophagus. ${ }^{30}$ Also, patients with BE have greater loss of esophageal body and LES function and a greater incidence of hiatal hernia compared to patients with erosive and nonerosive phenotypes. ${ }^{31}$ In addition, the combined exposure of esophageal mucosa to bile acids and low $\mathrm{pH}$ contributes to the cranial propagation of BE and results in DNA damage and oxidative stress. ${ }^{32,33}$ In population studies, a higher frequency of GERD symptoms is associated with an increased risk of BE. ${ }^{34,35}$ Interestingly, patients with BE report that long-lasting GERD symptoms improve over time, suggesting decreased esophageal sensitivity during $\mathrm{BE}$ development.

Although patients with a BMI $\geq 30 \mathrm{~kg} / \mathrm{m}^{2}$ have a threefold higher risk of developing EAC, the association between BMI and the risk of BE has been shown to be less consistent. ${ }^{36}$ Central visceral adiposity identified by increased waist circumference or waist-to-hip ratio has been associated with columnar metaplasia and $\mathrm{BE} .{ }^{37} \mathrm{~A}$ possible expla- nation is that central adiposity may increase gastroesophageal reflux by increasing intra-abdominal or intragastric pressure, partial hiatus herniation, and the transdiaphragmatic pressure gradient. ${ }^{38}$ In addition, proinflammatory cytokines (leptin, adiponectin, tumor necrosis factor- $\alpha$, interleukin- 6 , and insulin-like growth factor) expression is altered in individuals with central obesity. ${ }^{39}$

Regarding smoking and alcohol consumption, most population studies have shown a twofold increased risk of $\mathrm{BE}$ in patients with any smoking history, whereas data supporting an increased risk due to alcohol consumption remain inconclusive. ${ }^{40}$ There is a phenotypic variance for GERD from inheritable single-nucleotide polymorphisms, and there is a $77 \%$ and $88 \%$ genetic correlation between GERD and BE, and between GERD and EAC, respectively, suggesting a polygenic overlap for GERD with both BE and EAC. ${ }^{41}$

\section{Factors associated with reduced risk of $\mathrm{BE}$}

H. pylori infection has been shown to reduce the risk of EAC, ${ }^{42}$ although a causal association has not been established. On the other hand, the effect of H. pylori on the risk of BE has been less consistent, based on a meta-analysis of 12 case-control studies. ${ }^{43}$ A Cochrane review pooling data from two randomized clinical trials demonstrated only an effect on symptom relief, but not any major protective effect of PPI therapy on BE progression. ${ }^{44}$ There is some evidence that antireflux surgery by fundoplication promotes $\mathrm{BE}$ regression and prevents dysplasia formation, ${ }^{45-47}$ but two reviews comparing medical and surgical therapy have failed to show the protective effect of antireflux surgery. ${ }^{48,49}$ A recent meta-analysis found a significant reduction in the pooled incidence rate ratios of patients surgically treated after the year 2000. However, as the risk of EAC persists, ongoing endoscopic surveillance is still needed after antireflux surgery. ${ }^{50}$

The potential for cyclooxygenase enzymes (COX-2) inhibition through nonsteroidal antiinflammatory drugs, including aspirin, to prevent BE progression is supported by cohort and casecontrol studies, ${ }^{51,52}$ but additional outcome data are needed and the risk/benefit ratio is unclear. The use of statins has been shown to be significantly associated with a reduced risk of $\mathrm{BE}$ compared with controls. Therefore, future well-designed studies might prove the role of nonsteroidal anti-inflammatory 
drugs and statins as chemopreventive agents in patients with $\mathrm{BE} .{ }^{53}$ High intake of vegetables, fruits, and red meat may be inversely associated with the risk of developing $\mathrm{BE} .^{54} \mathrm{~A}$ population-based study also suggested that high dietary intake of magnesium significantly reduces the risk of reflux esophagitis and BE. ${ }^{55}$ Finally, a study, including 999 EAC patients, 2,061 BE patients, and 2,168 controls, found an inverse association with the risk of $\mathrm{BE}$ and EAC for every $10-\mathrm{cm}$ increase in body height. ${ }^{56}$

\section{Predictors of disease progression from BE to dysplasia and adenocarcinoma}

The epidemiology of EAC has become a major area of investigation over the past three decades due to the high lethality of the disease and the exponential increase in incidence rates. Less precise and consistent data are available for the epidemiology of its precursor, BE. In fact, the power of population studies is limited because BE is often minimally symptomatic and largely underdiagnosed, and the majority of patients have not undergone upper gastrointestinal endoscopy before EAC is discovered. This may be due to reduced access to endoscopy dictated by lack of public healthcare resources or excessive reliance in the symptomatic control of GERD. ${ }^{57,58}$ A screening study of 1,000 unselected residents in northern Sweden showed that $10.3 \%$ of individuals had endoscopic findings suggestive of BE, but IM was histologically confirmed in $1.6 \%$ of cases, ${ }^{59}$ giving a standard prevalence rate of 1-2\%. A large cohort study from the Netherlands found a linear increase in the incidence of detected BE from 14.3 to $23.1 / 100,000$ person years, and this finding was independent from the number of upper gastrointestinal endoscopies performed. Importantly, the incidence of EAC increased in the same period of time. ${ }^{60}$ A more recent meta-analysis of 51 studies, including patients from Asia, showed that the histologically proven pooled prevalence of BE was $1.3 \%$, thus comparable to Western estimates and indicating a similar potential to develop into EAC. ${ }^{61}$

The risk of developing EAC increases with age and is significantly greater in men, with a male-tofemale ratio of 6:1; also, men with $\mathrm{BE}$ are two to four times more likely to develop EAC compared with females. ${ }^{62-64}$ The timeline to diagnosis of $\mathrm{BE}$ is also a risk factor for malignant progression, as patients with a $\geq 10$-year history have a twofold risk of developing high-grade dysplasia (HGD) and EAC. ${ }^{65}$ It has been suggested that an increased waist-to-hip ratio and waist circumference is a risk factor for BE progression to EAC. ${ }^{66}$ No consistent association has been found with alcohol use, but tobacco use increases the risk of progression to HGD and EAC in patients with BE (HR 2.03), and current smokers have the highest risk. ${ }^{67,68}$

Long-standing, frequent, and severe GERD symptoms in patients with $\mathrm{BE}$ are associated with an increased risk of EAC. ${ }^{69}$ The length of BE is an additional risk factor for EAC. Annual cancer progression rates of patients with long- $(\geq 3 \mathrm{~cm})$, short- $(\geq 1$ to $<3 \mathrm{~cm})$, and ultrashort $(<1 \mathrm{~cm})$ segments were $0.22 \%, 0.03 \%$, and $0.01 \%$, respectively. ${ }^{70}$ Dysplastic BE has a higher risk of progression to EAC. The risk estimates vary considerably because of substantial interobserver and even intraobserver variations in histologic interpretation, especially for low-grade dysplasia (LGD). ${ }^{71}$ The incidence of HGD or EAC is as high as $13 \%$ per patient/year in patients in whom LGD is diagnosed through the consensus of expert pathologists in tertiary referral centers, ${ }^{72}$ and these data have supported the use of ablation therapy in patients with "true" LGD. ${ }^{73}$ Substantially higher progression rates are reported in patients with HGD, where endoscopic eradication is warranted. ${ }^{74}$ Biological markers to identify patients with $\mathrm{BE}$ at increased risk of progression are neither readily available nor validated in clinical practice. A number of studies and guidelines suggest the addition of p53 immunohistochemistry to improve the diagnosis of dysplasia and patient stratification, since the overexpression or loss of p53 protein expression could be a predictor of $\mathrm{BE}$ progression. ${ }^{75,76}$

\section{Is there a point of no return in the natural history of GERD?}

The development of mucosal changes typical of $\mathrm{BE}$ is a stepwise process. The first step is thought to be initiated by an inflammatory response to acid exposure of the squamous epithelium covering the effaced portion of the LES and by progressive replacement with metaplastic cardiac mucosa that fills the squamo-oxyntic gap. ${ }^{12,77}$ The next step consists of development of IM with goblet cells within the metaplastic cardiac mucosa. Esophageal exposure to a $\mathrm{pH}$ in the range of 3-5 resulting from mixing of gastric and duodenal juices, and saliva at the esophagogastric junction (EGJ) 
mucosal interface appears to initiate the process of intestinalization. There may be a time lag of 5-7 years after the onset of reflux symptoms for intestinalized cardiac mucosa to appear in adults. ${ }^{78}$ IM limited to the cardiac mucosa may still reverse after antireflux surgery. However, once visible segments of BE appear, IM is no longer reversible. At this stage, progressive deterioration of the LES and esophageal body function causes worsening of esophageal exposure to gastroduodenal contents and leads to defective esophageal contractility. ${ }^{79}$

Patients with established BE represent GERD on the severe end of the disease spectrum and often present with large hiatal hernias and acquired esophageal shortening. Even if heartburn is controlled with PPI, regurgitation commonly occurs and may require antireflux surgery for relief. Although the reported results of antireflux surgery appear satisfactory, ${ }^{80}$ the operation may be more challenging and the potential for breakdown of the repair higher compared with non-BE patients. Importantly, despite effective symptomatic treatment, the clinical course of $\mathrm{BE}$ cannot be altered at this late disease stage and there is likely a point of no return on the continuum from metaplasia to neoplasia in which EAC is inevitable. A randomized study comparing medical and surgical therapy did not show regression despite esophageal acid exposure normalization on $24 \mathrm{~h} \mathrm{pH}$ monitoring, but significantly less de novo dysplasia in the surgical group was observed. ${ }^{81}$ Actually, disease progression may occur especially in patients with a failed fundoplication. ${ }^{82}$ In a study comparing 55 patients who developed EAC more than 5 years after antireflux surgery and 240 matched controls, patients with EAC were three times more likely have recurrent pathologic reflux after surgery. ${ }^{83}$ Therefore, it may be logical to assume that a functioning fundoplication can reduce or at least stabilize the risk of EAC in some BE patients.

\section{Prevention of progressive GERD by laparoscopic fundoplication or lower esophageal sphincter augmentation}

Clinical signs of progressive disease include bipositional reflux on 24-h esophageal $\mathrm{pH}$ monitoring, an abnormal esophageal acid exposure on both days of a 48 -h BRAVO $^{\circledR}$ study, a defective LES on esophageal manometry, and/or persistent esophagitis despite medical therapy. More recently, the presence of IM at the EGJ has been recognized as a marker of progressive disease. ${ }^{84,85}$ Medical therapy is unable to prevent the development of $\mathrm{BE}$ or induce the regression of IM, the precursor of visible BE. Also, current endoscopic therapies cannot reduce and correct a hiatal hernia, and their effects on histopathology, including prevention of EAC, are unknown.

On the contrary, there is evidence, although limited, that laparoscopic antireflux surgery can prevent IM before endoscopically visible BE develops, reduce new $\mathrm{BE}$, and reduce new and existing dysplasia (especially LGD). ${ }^{45,46,81,86-89}$ Antireflux surgery is effective largely because of the control of both esophageal acid and bile exposure. However, it is important to note that fundoplication is not more effective than PPI on incident EAC. Despite the evidence, less than $1 \%$ of patients with persistent GERD symptoms refractory to PPI or with objective evidence of GERD progression are offered surgical therapy. ${ }^{6}$ This has been attributed to variability of outcomes depending on surgical expertise or surgical technique. A randomized trial of PPI versus laparoscopic antireflux surgery in a highly selected group of patients with refractory heartburn showed that treatment success with surgery was significantly superior to medical therapy ${ }^{90} \mathrm{~A}$ recent nationwide population-based cohort study on 2,655 patients who underwent primary laparoscopic antireflux surgery and were followed for a median of 5.6 years found a $17.7 \%$ incidence of recurrent reflux requiring medical therapy or reintervention. A lower recurrence rate was observed in a subgroup of men without comorbidities and aged 45 years or younger. ${ }^{91}$ The best outcomes are generally obtained in high-volume centers, where a multidisciplinary approach can be offered along with surgical expertise. Patient selection is critical, and patients with suspected functional heartburn and/or extraesophageal symptoms should be carefully tested before considering surgical therapy. ${ }^{92-94}$ The unpleasant, yet uncommon, side effects of the fundoplication (e.g., bloating) may account for low satisfaction rates and delayed patient referral. ${ }^{95}$

Laparoscopic implant of either magnetic or electrical LES augmentation has been proposed for patients with early-stage GERD to provide a less invasive surgical option and reduce the side effects of conventional fundoplication. ${ }^{96,97}$ Magnetic sphincter augmentation $\left(\right.$ LINX $^{\circledR}$ ) has proven 
safe and effective in controlling reflux symptoms, reducing PPI use, and decreasing esophageal acid exposure in several clinical studies. ${ }^{98,99}$ In a randomized study, the therapeutic response rate for refractory regurgitation at 1 year was $96 \%$ after the LINX procedure and 19\% with double-dose PPI therapy. ${ }^{100}$ The LINX procedure is less invasive than fundoplication because it involves very little dissection, as the short gastric vessels are not divided and the gastric fundus remains untouched. Standardization through precise measurement of the esophageal circumference and implant of a properly sized device are among the advantages of LINX. Reversion to normal anatomy and conversion to standard fundoplication are also safe and feasible laparoscopically. ${ }^{101,102}$ The combination of the LINX procedure with hiatal repair has been proven to be very effective. At 1-year follow-up, recurrent GERD symptoms and hiatal hernia were less frequent after complete hiatal dissection compared with minimal dissection without cruroplasty. ${ }^{103}$ In another study of 259 patients, ${ }^{104}$ a formal crural repair was also most likely to achieve normalization of postoperative DeMeester scores, confirming that hiatal closure clearly contributes to the manometric high-pressure zone and that competence of the antireflux barrier is explained by the "two-sphincter hypothesis." 105,106 In patients with uncomplicated GERD, the LINX procedure results in equivalent symptom control and improved quality of life with less side effects compared with the Nissen fundoplication. Interestingly, reversion of IM to cardiac mucosa has been documented in $72 \%$ of patients with $\mathrm{BE}$ at a median of 1.2 years after LINX. In patients with ultrashort-, short-, and long-segment $\mathrm{BE}$, the regression rates were $85.7 \%, 73.3 \%$, and $25 \%$, respectively, and no progression to dysplasia or EAC occurred. ${ }^{107}$ In a recent study, including 553 patients from a single center, independent predictors of a favorable outcome after the LINX procedure were age $<45$ years, male sex, GERDHRQL total score $>15$, and an abnormal DeMeester score. $^{108}$

\section{Prevention of EAC and histologic stabilization by endoscopic ablation with or without antireflux surgery}

Theoretically, if all metaplastic cells could be completely eradicated, the risk of progression of $\mathrm{BE}$ will be a rare occurrence or maybe even nonexistent.
The eradication strategy should be a multimodal therapeutic approach that includes endoscopic ablation and antireflux surgery, and if successfully implemented, it may avoid the need for continuous surveillance that has been shown to have little effect in preventing EAC. ${ }^{109,110}$ However, in practice, the outcome is not as ideal as one might expect it to be, and challenges include the quality of the endoscopic eradication strategy. ${ }^{111}$ Although level I evidence already exists for radiofrequency ablation (RFA) in both LGD and HGD, ${ }^{112}$ no convincing long-term data exist in support of RFA for nondysplastic BE. The American College of Gastroenterology Clinical Guidelines recommend ablative therapy for nonnodular dysplastic BE and T1a EAC, followed by endoscopic surveillance. According to these guidelines, neither fundoplication nor PPI is currently indicated after ablation therapy to prevent new EAC. ${ }^{113}$

Remission of dysplasia without achieving complete eradication of IM is associated with a significantly higher risk of recurrence. ${ }^{114}$ Thus, endoscopic ablation followed by fundoplication can be an attractive option. While stricture is a potential complication of this combined therapy, reported rates were relatively low at approximately $10 \%$. However, there is very limited evidence to indicate that the combined approach of ablation and fundoplication is effective. Limited evidence also indicates that the complete remission rate for IM and dysplasia is higher with combined therapy. ${ }^{115-117}$ Further larger randomized trials are needed before any firm recommendation may be made for the combined approach. At the moment, there are no data for endoscopy ablation in combination with magnetic or electrical LES augmentation, but this option may be considered if $\mathrm{BE}$ is short and without hiatal hernia in a young patient.

\section{Conclusion}

Progressive GERD can lead to the severe complications of erosive esophagitis, dysplastic $\mathrm{BE}$, and EAC. Better understanding of GERD in recent years has led to a paradigm shift from a largely symptom-based disorder to a spectrum and progressive disorder. Management of GERD could be improved and its complications decreased by changing the current paradigm that does not allow the identification of early-stage disease before IM develops at the squamocolumnar junction. Modern 
laparoscopic surgical therapy without or with endoscopic ablation has the potential to modify the clinical course of early-stage GERD in young patients and is an appealing option to improve the quality of life for individuals who otherwise would likely require decades of pharmacological therapy, with a significant burden on healthcare resources. However, more robust randomized trials and outcome data are needed before firm clinical recommendations can be made.

\section{Author contributions}

L.B. designed and wrote the first version of the manuscript. All authors provided critical scientific input, revised the manuscript, and agreed on the final version.

\section{Competing interests}

The authors declare no competing interests.

\section{References}

1. Eusebi, L., R. Ratnakumaran, Y. Yuan, et al. 2018. Global prevalence of, and risk factors for, gastro-oesophageal reflux symptoms: a meta-analysis. Gut 67: 430-440.

2. El-Serag, H.B., A. Becher \& R. Jones. 2010. Systematic review: persistent reflux symptoms on proton pump inhibitor therapy in primary care and community studies. Aliment. Pharmacol. Ther. 32: 720-737.

3. Richter, J.E. 2000. Gastroesophageal reflux disease in the older patient: presentation, treatment, and complications. Am. J. Gastroenterol. 95: 368-373.

4. Bammer, T., R.A. Hinder, A. Klaus, et al. 2002. Safety and long-term outcome of laparoscopic antireflux surgery in patients in their eighties and older. Surg. Endosc. 16: 40-42.

5. El Lakis, M.A., S.J. Kaplan, M. Hubka, et al. 2017. The importance of age on short-term outcomes associated with repair of giant paraesophageal hernias. Ann. Thorac. Surg. 103: 1700-1709.

6. Finks, J.F., Y. Wei \& J.D. Birkmeyer. 2006. The rise and fall of antireflux surgery in the United States. Surg. Endosc. 20: 1698-1701.

7. El-Serag, H.B., M.A. Gilger, M.D. Shub, et al. 2006. The prevalence of suspected Barrett's esophagus in children and adolescents: a multicenter endoscopic study. Gastrointest. Endosc. 64: 671-675.

8. Ness-Jensen, E., A. Lindam, J. Lagergren, et al. 2012. Changes in prevalence, incidence and spontaneous loss of gastro-oesophageal reflux symptoms: a prospective population-based cohort study, the HUNT study. Gut. 61: 1390-1397.

9. Inadomi, J., H. Alastal, L. Bonavina, et al. 2018. Recent advances in Barrett's esophagus. Ann. N.Y. Acad. Sci. 1434: 227-238.
10. Savarino, E., N. De Bortoli, C. De Cassan, et al. 2017. The natural history of gastro-esophageal reflux disease: a comprehensive review. Dis. Esophagus 30: 1-9.

11. Vakil, N., S.V. van Zanten, P. Kahrilas, et al. 2006. The Montreal definition and classification of gastroesophageal reflux disease: a global evidence-based consensus. Am. J. Gastroenterol. 101: 1900-1920.

12. Chandrasoma, P., S. Wijetunge, S.R. DeMeester, et al. 2010. The histologic squamo-oxyntic gap: an accurate and reproducible diagnostic marker of gastroesophageal reflux disease. Am. J. Surg. Pathol. 34: 1574-1581.

13. Pace, F., S. Bollani, P. Molteni, et al. 2004. Natural history of gastroesophageal reflux disease without esophagitis (NERD) - a reappraisal 10 years on. Dig. Liver Dis. 36: 111-115.

14. Pace, F. \& G. Bianchi Porro. 2004. Gastroesophageal reflux disease: a typical spectrum disease (a new conceptual framework is not needed). Am. J. Gastroenterol. 99: 946949.

15. Labenz, J., M. Nocon, T. Lind, et al. 2006. Prospective follow-up data from the ProGERD studty suggest that GERD is not a categorical disease. Am. J. Gastroenterol. 101: 2457-2462.

16. Fullard, M., J.Y. Kang, P. Neild, et al. 2006. Systematic review: does gastro-oesophageal reflux disease progress? Aliment. Pharmacol. Ther. 24: 33-45.

17. Nilsson, M., R. Johnsen, W. Ye, et al. 2004. Prevalence of gastro-oesophageal reflux symptoms and the influence of age and sex. Scand. J. Gastroenterol. 39: 10401045.

18. Lin, M., L.B. Gerson, R. Lascar, et al. 2004. Features of gastroesophageal reflux disease in women. Am. J. Gastroenterol. 99: 1442-1447.

19. Kim, Y.S., N. Kim \& G.H. Kim. 2016. Sex and gender differences in gastroesophageal reflux disease. J. Neurogastroenterol. Motil. 22: 575-588.

20. Ford, A., D. Forman, P.D. Reynolds, et al. 2005. Ethnicity, gender, and socioeconomic status as risk factors for esophagitis and Barrtt's esophagus. Am. J. Epidemiol. 162: 454-460.

21. El-Serag, H.B. \& J.F. Johanson. 2002. Risk factors for severity of erosive esophagitis in Helicobacter pylori-negative patients with gastroesophageal reflux disease. Scand. J. Gastroenterol. 37: 899-904.

22. Derakhshan, M.H., S. Liptrot, J. Paul, et al. 2009. Oesophageal and gastric intestinal-type adenocarcinomas show the same male predominance due to a 17 year delayed development in females. Gut 58: 16-23.

23. Adeniyi, K.O. 1991. Gastric acid secretion and parietal cell mass: effect of sex hormones. Gastroenterology 101: 66-69.

24. Masaka, T., I. Katsunori, H. Endo, et al. 2013. Gender differences in oesophageal mucosal injury in a reflux oesophagitis model of rats. Gut 62: 6-14.

25. Juhasz, A., S.K. Mittal, T.H. Lee, et al. 2011. Prevalence of Barrett's esophagus in first degree relatives of patients with esophageal adenocarcinoma. J. Clin. Gastroenterol. 45: 867-871.

26. Sun, X., R.C. Elston, J.S. Barnholtz-Sloan, et al. 2016. Predicting Barrett's esophagus in families: an esophagus translational research network (BETRNet) model fitting clinical 
data to a familial paradigm. Cancer Epidemiol. Biomarkers Prev. 25: 727-735.

27. Malfertheiner, P., M. Nocon, M. Vieth, et al. 2012. Evolution of gastro-oesophageal reflux disease over 5 years under routine medical care-the Pro-GERD study. Aliment. Pharmacol. Ther. 35: 154-164.

28. Falkenback, D., S. Oberg, F. Johnsson, et al. 2009. Is the course of gastroesophageal reflux disease progressive? A 21-year follow-up. Scand. J. Gastroenterol. 33: 12771287.

29. Lord, R.V., S.R. DeMeester, J.H. Peters, et al. 2009. Hiatal hernia, lower esophageal sphincter incompetence, and effectiveness of Nissen fundoplication in the spectrum of gastroesophageal reflux disease. J. Gastrointest. Surg. 13: 602-610.

30. Fass, R., R.W. Hell, H.S. Garewal, et al. 2001. Correlation of oesophageal acid exposure with Barrett's oesophagus length. Gut 48: 310-313.

31. Oberg, S., T.R. DeMeester, J.H. Peters, et al. 1999. The extent of Barrett's esophagus depends on the status of the lower esophageal sphincter and the degree of esophageal acid exposure. J. Thorac. Cardiovasc. Surg. 117: 572-580.

32. Vaezi, M.F. \& J.E. Richter. 1996. Role of acid and duodenogastroesophageal reflux in gastroesophageal reflux disease. Gastroenterology 111: 1192-1199.

33. Dvorak, K., C.M. Payne, M. Chavarria, et al. 2007. Bile acids in combination with low $\mathrm{pH}$ induce oxidative stress and oxidative DNA damage: relevance to the pathogenesis of Barrett's oesophagus. Gut 56: 763-771.

34. Johansson, J., H.O. Hakansson, L. Mellblom, et al. 2007. Risk factors for Barrett's esophagus: a population-based approach. Scand. J. Gastroenterol. 42: 148-156.

35. Anderson, L.A., R.G. Watson, S.J. Murphy, et al. 2007. Risk factors for Barrett's oesophagus and oesophageal adenocarcinoma: results from the FINBAR study. World J. Gastroenterol. 13: 1585-1594.

36. El-Serag, H.B., P. Kvapil J. Hacken-Bitar \& J.R. Krmaer. 2005. Abdominal obesity and the risk of Barrett's esophagus. Am. J. Gastroenterol. 100: 2151-2156.

37. Derakhshan, M.H., E.V. Robertson, Y.Y. Lee, et al. 2015. In healthy volunteers, immunohistochemistry supports squamous to columnar metaplasia as mechanism of expansion of cardia, aggravated by central obesity. Gut 64: 1705-1714.

38. Lee, Y.Y., A.A. Wirz, J.G.H. Whiting, et al. 2014. Waist belt and central obesity cause partial hiatus hernia and shortsegment acid reflux in asymptomatic volunteers. Gut 63: 1053-1060.

39. Thompson, O.M., S.A. Beresford, E.A. Kirk, et al. 2010. Serum leptin and adiponectin levels and risk of Barrett's esophagus and intestinal metaplasia of the gastroesophageal junction. Obesity 18: 2204-2211.

40. Andrici, J., M.R. Cox \& G.D. Eslick. 2013. Cigarette smoking and the risk of Barrett's esophagus: a systematic review and meta-analysis. J. Gastroenterol. Hepatol. 28: 12581273.

41. Gharahkhani, P., J. Tung, D. Hinds, et al. 2015. Chronic gastroesophageal reflux disease shares genetic background with esophageal adenocarcinoma and Barrett's esophagus. Hum. Mol. Genet. 25: ddv512-ddv835.
42. Islami, F. \& F. Kamangar. 2008. Helicobacter pylori and esophageal cancer risk: a meta-analysis. Cancer Prev. Res. 1: 329-338.

43. Wang, C., Y. Yuan \& R.H. Hunt. 2009. Helicobacter pylori infection and Barrett's esophagus: a systematic review and meta-analysis. Am. J. Gastroenterol. 104: 492-500.

44. Rees, J.R., P. Lao-Sirieix, A. Wong, et al. 2010. Treatment for Barrett's oesophagus. Cochrane Database Syst. Rev. CD004060 .

45. Hofstetter, W.L., J.H. Peters, T.R. DeMeester, et al. 2001. Long-term outcome of antireflux surgery in patients with Barrett's esophagus. Ann. Surg. 234: 532-538.

46. O’Riordan, J.M., P.J. Byrne, N. Ravi, et al. 2004. Long-term clinical and pathologic response of Barrett's esophagus after antireflux surgery. Am. J. Surg. 188: 27-33.

47. Oberg, S., J. Wenner, J. Johansson, et al. 2005. Barrett esophagus: risk factors for progression to dysplasia and adenocarcinoma. Ann. Surg. 242: 49-54.

48. Corey, K.E., S.M. Schmitz \& N.J. Shaheen. 2003. Does a surgical antireflux procedure decrease the incidence of esophageal adenocarcinoma in Barrett's esophagus? A meta-analysis. Am. J. Gastroenterol. 98: 2390-2394.

49. Chang, E.Y., C.D. Morris, A.K. Seltman, et al. 2007. The effect of antireflux surgery on esophageal carcinogenesis in patients with Barrett's esophagus: a systematic review. Ann. Surg. 246: 11-21.

50. Maret-Ouda, J., P. Konings, J. Lagergren, et al. 2016. Antireflux surgery and risk of oesophageal adenocarcinoma. Ann. Surg. 263: 251-257.

51. Cuzick, J., M.A. Thorat, C. Bosetti, et al. 2014. Estimates of benefits and harms of prophylactic use of aspirin in the general population. Ann. Oncol. 26: 47-57.

52. Wang, F., Z.S. Lv \& Y.K. Fu. 2011. Non-steroidal antinflammatory drugs and esophageal inflammation-Barrett's esophagus-adenocarcinoma sequence: a meta-analysis. Dis. Esophagus 24: 318-324.

53. Beales, I.L., L. Dearman, I. Vardi, et al. 2015. Reduced risk of Barrett's esophagus in statin users: case-control study and meta-analysis. Dig. Dis. Sci. 61: 238-246.

54. Kubo, A., G. Block, C.P. Quesenberry, et al. 2009. Effects of dietary fiber, fats, and meat intakes on the risk of Barrett's esophagus. Nutr. Cancer 61: 607-616.

55. Dai, Q., M.M. Cantwell, L.J. Murray, et al. 2016. Dietary magnesium, calcium:magnesium ratio and risk of reflux oesophagitis, Barrett's oesophagus and oesophageal adenocarcinoma: a population-based case-control study. Br. J. Nutr. 115: 342-350.

56. Thrift, A.P., H.A. Risch, L. Onstad, et al. 2014. Risk of esophageal adenocarcinoma decreases with height, based on consortium analysis and confirmed by Mendelian randomization. Clin. Gastroenterol. Hepatol. 12: 1667-1676.

57. Incarbone, R., L. Bonavina, S. Szachnowicz, et al. 2000. Rising incidence of esophageal adenocarcinoma in western countries: is it possible to identify a population at risk? Dis. Esophagus 13: 275-278.

58. Incarbone, R., L. Bonavina, G. Saino, et al. 2002. Outcome of esophageal adenocarcinoma detected during endoscopic biopsy surveillance of Barrett's esophagus. Surg. Endosc. 16: 263-266. 
59. Ronkainen, J., P. Aro, T. Storskrubb, et al. 2005. Prevalence of Barrett's esophagus in the general population: an endoscopic study. Gastroenterology 129: 1825-1831.

60. Van Soest, E.M., J.P. Dieleman, P.D. Siersema, et al. 2005. Increasing incidence of Barrett's oesophagus in the general population. Gut 54: 1062-1066.

61. Shiota, S., S. Singh, A. Anshasi, et al. 2015. Prevalence of Barrett's esophagus in Asian countries: a systematic review and meta-analysis. Clin. Gastroenterol. Hepatol. 13: 19071918.

62. Conio, M., A.J. Cameron, Y. Romero, et al. 2001. Secular trends in the epidemiology and outcome of Barrett's oesophagus in Olmsted County, Minnesota. Gut 48: 304309.

63. Edgren, G., H.O. Adami, E. Weiderpass, et al. 2013. A global assessment of the oesophageal adenocarcinoma epidemic. Gut 62: 1406-1414.

64. Xie, S.H. \& J. Lagergren. 2016. The male predominance in esophageal adenocarcinoma. Clin. Gastroenterol. Hepatol. 14: 338-347.

65. Bhat, S.K., D.T. McManus, H.G. Coleman, et al. 2015. Oesophageal adenocarcinoma and prior diagnosis of Barrett's oesophagus: a population-based study. Gut 64: 20-25.

66. Sikkema, M., C.W. Looman, E.W. Steyerberg, et al. 2011. Predictors for neoplastic progression in patients with Barrett's esophagus: a prospective cohort study. Am. J. Gastroenterol. 106: 1231-1238.

67. Hardikar, S., L. Honstad, P.L. Blount, et al. 2013. The role of tobacco, alcohol, and obesity in neoplastic progression to esophageal adenocarcinoma: a prospective study of Barrett's esophagus. PLoS One 8. e52192.

68. Coleman, H.G., S. Bhat, B.T. Johnston, et al. 2012. Tobacco smoking increases the risk of high-grade dysplasia and cancer among patients with Barrett's esophagus. Gastroenterology 142: 233-240.

69. Lagergren, J., R. Bergstrom, A. Lindgren, et al. 1999. Symptomatic gastroesophageal reflux as a risk factor for esophageal adenocarcinoma. N. Engl. J. Med. 340: 825-831.

70. Pohl, H., O. Pech, H. Arash, et al. 2016. Length of Barrett's oesophagus and cancer risk: implications from a large sample of patients with early oesophageal adenocarcinoma. Gut 65: 196-201.

71. Montgomery, E., M.P. Bronner, J.R. Goldblum, et al. 2001. Reproducibility of the diagnosis of dysplasia in Barrett esophagus: a reaffirmation. Hum. Pathol. 32: 368-378.

72. Duits, L.C., K.N. Phoa, W.L. Curvers, et al. 2015. Barrett's oesophagus patients with low-grade dysplasia can be accurately risk-stratified after histological review by an expert pathology panel. Gut 64: 700-706.

73. Phoa, K.N., F.G. van Vilsteren, B.L. Weusten, et al. 2014. Radiofrequency ablation vs endoscopic surveillance for patients with Barrett esophagus and low-grade dysplasia: a randomized clinical trial. JAMA 311: 1209-1217.

74. Greene, C.L., S.G. Worrell, S.E. Attwood, et al. 2016. Emerging concepts for the endoscopic management of superficial esophageal adenocarcinoma. J. Gastrointest. Surg. 20: 851-860.

75. Kastelein, F., K. Biermann, E.W. Steyerberg, et al. 2013. Aberrant p53 protein expression is associated with an increased risk of neoplastic progression in patients with Barrett's oesophagus. Gut 62: 1676-1683.

76. Fitzgerald, R.C., M. Di Pietro, K. Ragunath, et al. 2014. British Society of Gastroenterology guidelines on the diagnosis and management of Barrett's oesophagus. Gut 63: $7-42$.

77. Oberg, S., J.H. Peters, T.R. DeMeester, et al. 1997. Inflammation and specialized intestinal metaplasia of cardiac mucosa is a manifestation of gastroesophageal reflux disease. Ann. Surg. 226: 522-532.

78. Qualman, S.J., R.D. Murray, J. McClung, et al. 1989. Intestinal metaplasia is age related in Barrett's esophagus. Arch. Pathol. Lab. Med. 114: 1236-1240.

79. DeMeester, S.R., G.M. Campos, T.R. DeMeester, et al. 1998. The impact of an antireflux procedure on intestinal metaplasia of the cardia. Ann. Surg. 228: 547-556.

80. Oelschlager, B.K., M. Barreca, L. Chang, et al. 2003. Clinical and pathological response of Barrett's esophagus to laparoscopic antireflux surgery. Ann. Surg. 238: 458-464.

81. Parrilla, P., L.F. Martinez de Haro, A. Ortiz, et al. 2003. Long-term results of a randomized prospective study comparing medical and surgical treatment of Barrett's esophagus. Ann. Surg. 237: 291-298.

82. Zehetner, J., S.R. DeMeester, S. Ayazi, et al. 2010. Longterm follow-up after antireflux surgery in patients with Barrett's esophagus. J. Gastrointest. Surg. 14: 1483-1491.

83. Lofdahl, H.E., Y. Lu, P. Lagergren, et al. 2013. Risk factors for esophageal adenocarcinoma after antireflux surgery. Ann. Surg. 257: 579-582.

84. Labenz, J., T.R. DeMeester, P. Chandrasoma, et al. 2018. Proposed approach to the challenging management of progressive gastroesophageal reflux disease. World J. Gastrointest. Endosc. 10: 175-183.

85. Pinto, D., W. Plieschnegger, N.I. Schneider, et al. 2019. Carditis: a relevant marker of gastroesophageal reflux disease. Data from a prospective central European multicenter study on histological and endoscopic diagnosis of esophagitis (histoGERD trial). Dis. Esophagus 32. https: //doi.org/10.1093/dote/doy073.

86. Wetscher, G.J., M. Gadenstaetter, P.J. Klingler, et al. 2001. Efficacy of medical therapy and antireflux surgery to prevent Barrett's metaplasia in patients with gastroesophageal reflux disease. Ann. Surg. 234: 627-632.

87. Abbas, A.E., C. Deschamps, S.D. Cassivi, et al. 2004. Barrett's esophagus: the role of laparoscopic fundoplication. Ann. Thorac. Surg. 77: 393-396.

88. Rossi, M., M. Barreca, N. de Bortoli, et al. 2006. Efficacy of Nissen fundoplication versus medical therapy in the regression of low-grade dysplasia in patients with Barrett esophagus: a prospective study. Ann. Surg. 243: 58-63.

89. Csendes, A., G. Smok, P. Burdiles, et al. 2008. Barrett's esophagus can develop after antireflux surgery. Eur. Surg. 40: $245-252$.

90. Spechler, S.J., J.G. Hunter, K.M. Jones, et al. 2019. Randomized trial of medical versus surgical treatment for refractory heartburn. N. Engl. J. Med. 381: 1513-1523.

91. Maret-Ouda, J., K. Wahlin, H.B. El-Serag, et al. 2017. Association between laparoscopic antireflux surgery and recurrence of gastroesophageal reflux. JAMA 318: 939-946. 
92. Triadafilopoulos, G., J.O. Clarke \& M. Hawn. 2017. Precision GERD management for the 21st century. Dis. Esophagus 30: 1-6.

93. Lee, Y.Y. \& J.C.Y. Wu. 2018. Management of patients with functional heartburn. Gastroenterology 154: 2018-2021.

94. Katzka, D.A., J.E. Pandolfino \& P.J. Kahrilas. 2020. Phenotypes of gastroesophageal reflux disease: where Rome, Lyon, and Montreal meet. Clin. Gastroenterol. Hepatol. 18: 767-776.

95. Richter, J.E. \& D.T. Dempsey. 2008. Laparoscopic antireflux surgery: key to success in the community setting. Am. J. Gastroenterol. 103: 289-291.

96. Bonavina, L. \& S. Attwood. 2016. Laparoscopic alternatives to fundoplication for gastroesophageal reflux: the role of magnetic augmentation and electrical stimulation of the lower esophageal sphincter. Dis. Esophagus 29: 996-1001.

97. Rieder, E., M. Riegler, A.P. Simic, et al. 2018. Alternative therapies for GERD: a way to personalized antireflux surgery. Ann. N.Y. Acad. Sci. 1434: 360-369.

98. Bonavina, L., G. Saino, D. Bona, et al. 2013. One hundred consecutive patients treated with magnetic sphincter augmentation for gastroesophageal reflux disease: 6 years of clinical experience from a single center. J. Am. Coll. Surg. 217: 577-585.

99. Ganz, R.A., S.A. Edmundowicz, P.A. Taiganides, et al. 2016. Long-term outcomes of patients receiving a magnetic sphincter augmentation device for gastroesophageal reflux. Clin. Gastroenterol. Hepatol. 14: 671-677.

100. Bell, R., J. Lipham, B. Louie, et al. 2019. Magnetic sphincter augmentation superior to proton pump inhibitors for regurgitation in a 1-year randomized trial. Clin. Gastroenterol. Hepatol. https://doi.org/10.1016/j.cgh.2019.08.056.

101. Asti, E., S. Siboni, V. Lazzari, et al. 2017. Removal of the magnetic sphincter augmentation device. Surgical technique and results of a single-center cohort study. Ann. Surg. 265: 941-945.

102. Tatum, J.M., E. Alicuben, N. Bildzukewicz, et al. 2019. Removing the magnetic sphincter augmentation device: operative management and outcomes. Surg. Endosc. 33: 2663-2669.

103. Tatum, J.M., E. Alicuben, N. Bildzukewicz, et al. 2019. Minimal versus obligatory dissection of the diaphragmatic hiatus during magnetic sphincter augmentation surgery. Surg. Endosc. 33: 782-788.

104. Irribarra, M.M., S. Blitz, C.L. Wilshire, et al. 2019. Does treatment of the hiatus influence the outcomes of magnetic sphincter augmentation for chronic GERD? J. Gastrointest. Surg. 23: 1104-1112.
105. Mittal, R.K., D.F. Rochester \& R.W. McCallum. 1997. Effect of the diaphragmatic contraction on lower oesophageal sphincter pressure in man. Gut 28: 1564-1568.

106. Louie, B.E., S. Kapur, M. Blitz, et al. 2013. Length and pressure of the reconstructed lower esophageal sphincter is determined by both crural closure and Nissen fundoplication. J. Gastrointest. Surg. 17: 236-243.

107. Alicuben, E.T., J.M. Tatum, N. Bildzukewicz, et al. 2019. Regression of intestinal metaplasia following magnetic sphincter augmentation. Surg. Endosc. 33: 576-579.

108. Ayazi, S., P. Zheng, A.H. Zaidi, et al. 2020. Clinical outcome and predictors of favorable result after laparoscopic magnetic sphincter augmentation: single institution experience with over 500 patients. J. Am. Coll. Surg. https://doi.org/10. 1016/j.jamcollsurg.2020.01.026.

109. Triafilopoulos, G. \& S. Friedland. 2018. Precision care for Barrett's esophagus. Transl. Gastroenterol. Hepatol. 3: 67.

110. Que, J., K.S. Garman, R.F. Souza, et al. 2019. Pathogenesis and cells of origin of Barrett's esophagus. Gastroenterology 157: 349-364.

111. Wani, S., V.R. Muthusamy, N.J. Shaheen, et al. 2017. Development of quality indicators for endoscopic eradication therapies in Barrett's esophagus: the TREAT-BE (Treatment with Resection and Endoscopic Ablation Techniques for Barrett's Esophagus) Consortium. Am. J. Gastroenterol. 112: 1032-1048.

112. Shaheen, N.J., B.F. Overholt, R.E. Sampliner, et al. 2011. Durability of radiofrequency ablation in Barrett's esophagus with dysplasia. Gastroenterology 141: 460-468.

113. Shaheen, N.J., G.W. Falk, P.G. Iyer, et al. 2016. ACG clinical guideline: diagnosis and management of Barrett's esophagus. Am. J. Gastroenterol. 111: 30-50.

114. Sawas, T., M. Alsawas, F. Bazerbachi, et al. 2019. Persistent intestinal metaplasia after endoscopic eradication therapy of neoplastic Barrett's esophagus increases the risk of dysplasia recurrence: meta-analysis. Gastrointest. Endosc. 89: 913-925.

115. O'Connell, K. \& V. Velanovich. 2011. Effects of Nissen fundoplication on endoscopic endoluminal radiofrequency ablation of Barrett's esophagus. Surg. Endosc. 25: 830-834.

116. Johnson, C.S., B.E. Louie, A. Wille, et al. 2015. The durability of endoscopic therapy for treatment of Barrett's metaplasia, dysplasia and mucosal cancer after Nissen fundoplication. J. Gastrointest. Surg. 19: 799-805.

117. Skrobic, O., A. Simic, N. Radovanovic, et al. 2016. Significance of Nissen fundoplication after endoscopic radiofrequency ablation of Barrett's esophagus. Surg. Endosc. 30: 3802-3807. 